\title{
COILing diverse islands: a virtual exchange between the University of the Bahamas and the Borough of Manhattan Community College
}

\author{
Raymond Oenbring ${ }^{1}$ and Deniz Gokcora ${ }^{2}$
}

\section{Abstract}

$\longrightarrow$ his practice report describes a Collaborative Online International Learning (COIL) exchange between academic writing students at the University of the Bahamas (UB)

and English Language Learners (ELLs) at the Borough of Manhattan Community College (BMCC) of the City University of New York (CUNY). While COIL projects and other classroom virtual exchanges between Western and non-Western institutions have often been construed as tools to introduce cultural and linguistic diversity into Western classrooms, this study shows that the opposite is also possible. In our project, a diverse, largely immigrant group of postsecondary students in New York City participated in an intercultural exchange with a more culturally and linguistically homogeneous student group in The Bahamas. The study details the digital media used to initiate the virtual exchange and the specifics of the assignment sequences, including how the authors worked with the springboard text read by both classes (that is, Richard Rodriguez's (1978) noted literacy autobiography 'The Achievement of Desire', where he describes his academic ambitions as the child of Mexican immigrants to the United States).

\section{Keywords: COIL; diversity; The Bahamas; English composition; ELL.}

\footnotetext{
1. University of the Bahamas, The Bahamas; raymond.oenbring@ub.edu.bs; https://orcid.org/0000-0003-2438-1920

2. Borough of Manhattan Community College, United States; sgokcora@bmcc.cuny.edu; https://orcid.org/0000-0003-3709-8139

How to cite this article: Oenbring, R., \& Gokcora, D. (2022). COILing diverse islands: a virtual exchange between the University of the Bahamas and the Borough of Manhattan Community College. Journal of Virtual Exchange, 5, 20-30. https://doi.org/10.21827/jve.5.37388
} 


\section{Introduction}

As a set of pedagogical modalities that has been in development for some 20 years, a significant body of scholarly literature has developed on virtual exchange (O’Reilly, 2021; Wylie, 2020). In virtual exchange, also known as COIL (see Moore \& Simon, 2015; SUNY COIL Center, 2017), students from learning institutions in two or more countries work together in a digital environment on a shared activity, and in so doing they have an opportunity to build cultural competencies and deepen intercultural understanding - along with learning course content. However, a significant limitation of COIL discourse is that some studies have displayed Western-centric frames of reference, often implicitly construing non-Western participants in COIL exchanges as an exoticized other bringing diversity to the curriculum. That is to say, COIL collaborations have sometimes been understood as strategies that can be used to introduce cultural and linguistic diversity into ethnically homogeneous classrooms in Western nations (e.g. Mudiamu, 2020). However, COIL projects can also be used to expand perspectives on culture, national belonging, and language in seeming monocultures outside of Western nations, with the Western institution being used to introduce diversity. In this article, we describe a COIL exchange between diverse multilingual ELL students at a community college in New York City and academic writing students at UB. For our COIL exchange, we established several layers of formal objectives, including intercultural learning, subject matter learning, and technical competency. In our COIL partnership, New York City provided a complex multicultural and multilingual environment to stimulate intercultural exchange with a more ethnically and linguistically homogeneous group of postsecondary students in The Bahamas.

\section{Literature review}

In the existing research literature on COIL, scholars have described virtual exchanges between a wide variety of student groups, including: students at different levels (e.g. between undergraduate and graduate-level courses in the same field Kayumova \& Sadykova, 2016); and between courses in the same field of study at the same level (e.g. uniting two international business courses BenbunanFich \& Arbaugh, 2006; Marcillo-Gómez \& Desilus, 2016). While academic writing scholars are finding classroom arrangements involving collaboration between traditional academic writing students and ELL students promising for promoting student success (Comeau-Kirschner \& Sharar, 2019), the literature describing COIL collaborations between developmental ELL classes with traditional academic writing courses is limited. In particular, nonnative speaking immigrant students have not received enough attention in the research on COIL. This study begins to fill these gaps in the research literature. 
Outside the COIL research tradition, the potential of using digital collaboration to build connections between Caribbean postsecondary classrooms and the outside world in order to expand students' perspectives was perhaps first recognized by Winner and Shields (2002). In the study, Winner and Shields describe their experience leading Bahamian college students through an online cultural exchange with students at a historically Black college in the American South. As Winner and Shields (2002) note, "the act of publishing a literacy autobiography on the [internet] for an English course at a college located on a small island in The Bahamas gave geographically isolated writers an opportunity to consider the intricate powers of language, and their space in the larger social and cultural influences of language learning” (p. 273). While the piece does not focus in major part on diversity issues, the Winner and Shields study does, however, suggest that the interaction with students abroad through a digital platform was "the best way to provide a socially and culturally diverse writing and learning experience” (Winner \& Shields, 2002, p. 275, emphasis added) for Bahamian students despite the rudimentary technology available for the exchange at the time.

\section{Context}

The current project was conducted at two postsecondary institutions serving significant numbers of socioeconomically-disadvantaged students: the UB main campus in Nassau, The Bahamas and BMCC, one of the five community colleges in the CUNY system. Having transitioned from a college to a fledgling university in 2016, UB is the national institution of higher education in The Bahamas. UB's student body is almost exclusively Black Bahamian Christian, who speak a combination of Bahamian Creole English (their L1) and (Bahamian) Standard English. This is not, however, to say that ethnic diversity does not exist in The Bahamas; The Bahamas has migrant populations from elsewhere in the Caribbean, as well as Latin America and Asia. However, this ethnic diversity does not significantly manifest itself in UB's student body. Furthermore, The Bahamas, like many other Caribbean nations, lacks widely institutionalized diversity accommodation discourses (Sairsingh et al., 2020). Indeed, although a number of UB students are first- or second-generation Haitian immigrants, who may or may not speak Haitian Creole at home, these students are usually keen to assimilate to English-speaking and Bahamian-Creole-English-speaking culture due to the stigma facing the Haitian minority in The Bahamas (Perry, 2020).

BMCC is, on the other hand, a highly diverse and multilingual campus; its student body is highly international, and over $88 \%$ of students are ethnic minorities in the United States (CUNY Borough of Manhattan Community College, 2020). As an example, the specific class that participated in the COIL project included students stemming originally from all of the following nations: the Dominican Republic, China, Bangladesh, the Republic of Georgia, Uzbekistan, Ghana, and Montenegro. 
At UB, students from one section of English 119, the first of the institution's first-year academic writing courses, participated in the COIL exchange. In English 119, students produce a variety of written assignments, such as summaries and annotated bibliographies, leading to the production of a research essay involving academic sources. Conversely, at BMCC, the participating students were enrolled in ESL 95, a not-for-credit developmental writing course which focuses on basic components of effective writing, including essay organization, paragraph development, sentence structure, word choice, and content.

The COIL project was designed and implemented by an ELL professor at BMCC and an academic writing professor at UB who had been connected with one another through the study abroad program at BMCC. These two professors, also the authors of this piece, each brought one section of their students to the COIL exchange. For brevity of expression, the two investigator-authors refer to themselves as 'we' in this study.

\section{Objectives}

We established several layers of formal objectives for our COIL collaboration which were explicitly communicated to students during the first joint Zoom meeting. These formal objectives included the following.

- Intercultural learning. We designed the overarching COIL project to give students an opportunity for rich intercultural learning, with intercultural learning being understood for our purposes according to the knowledge, attitude, skills, and awareness model (Fantini \& Tirmizi, 2006). Student activities in the COIL project included activities such as interviewing each other. The global social justice project also enabled students to learn from each other regarding social justice issues around the world.

- Subject matter learning objective. A primary objective of any COIL exchange should be closely tied to the overarching pedagogical goals of the courses they are enrolled in at their home institutions. Accordingly, we aimed to connect the COIL tasks to building students' academic writing skills.

- Technical competency. As students participated in the COIL exchange, they would gain experience using a variety of technologies and platforms, including: the CBOX learning management system, Zoom (both for COIL meetings and for screencasting their global social justice video), and YouTube. 


\section{Project design}

For the COIL project, we designed a series of assignments and activities aimed to encourage intercultural learning. Following the suggestions of scholars such as O'Dowd and Dooly (2020), we specifically structured the assignment tasks to lead to purposeful engagement highlighting both the differences and similarities between the student groups. In our case, we focused specifically on differences in attitudes to language learning and academic pursuits in students' home cultures. That is to say, we attempted to refocus our "online intercultural exchange so that there is a genuine engagement with and negotiation of difference” (O’Dowd \& Dooly, 2020, p. 368) rather than simple "surfing diversity" (see Kramsch, 2014, p. 302). Our working hypothesis was that a well-designed COIL exchange would facilitate intercultural learning between traditionally diverse students in a Western nation and a more homogenous group in a non-Western nation.

In order to achieve these aims, the first assignment sequence used Richard Rodriguez's (1978) noted work describing his literacy development as the child of first-generation Mexican immigrants to the United States, 'The Achievement of Desire', as the initial springboard reading assignment. We believed that Rodriguez's work would be fruitful in our COIL collaboration because it describes the academic ambitions of an 'outsider' to the English language in English-speaking academic institutions (recall that the Bahamian students are native speakers of Bahamian Creole English rather than Bahamian Standard English; they too are 'outsiders' to the English language). Furthermore, the Rodriguez piece draws explicit attention to immigrant experiences, something BMCC students could directly relate to, and something we believed that UB students would benefit from considering in greater depth.

After our first joint COIL meeting on Zoom, and once the students had read the Rodriguez piece, we next paired students up from the different institutions. We instructed them to meet with one another twice to interview their partners regarding their educational backgrounds and the cultural contexts of literacy, language learning, and education in their respective home nations. In order to keep these engagements structured, we provided a number of guiding questions for the interviews, which students then used to produce a report on their partner's answers to post to the COIL message board hosted on an independent implementation of the CUNY Academic Commons CBOX platform.

In each class, this assignment sequence ended with students drafting complete formal essays, but the essay prompts were somewhat different in the different classes as the UB students were at a higher level. BMCC ELL students were asked to compose an expository essay summarizing their COIL partner's college experiences gathered from the second interview report and were required to back it up by providing references from Rodriguez's piece. Conversely, the UB students were asked to write an essay comparing the contexts of language learning in The Bahamas with their 
COIL partner's home nation, referring not only to the second interview, but also including ideas and evidence from research articles.

For the second assignment sequence in the class, what we called the global social justice video assignment, we asked students to select an image or advertisement reflecting a significant social justice issue in their home country (e.g. violence against women). Students then produced a video assignment analyzing the image according to the Aristotelian rhetorical appeals of ethos, pathos, and logos, as well as the cultural background of the social issue, posting the video to YouTube and embedding or linking to the video in our joint learning management system. As part of our scaffolding for the global social justice video assignment, we hosted six optional 'drop-in' Zoom meetings with students to give them examples of global social justice topics (as many of them were unfamiliar with the concept) and to help them flesh out their approaches.

Also of note is the fact that the study took place during the fall 2020 academic semester when both institutions were operating under remote-only learning due to the COVID-19 pandemic. That is to say, not all students were equally technologically adept, and some students would have preferred being enrolled in classes that had face-to-face meetings instead. Further, for most of our students, this online semester was their first semester at their respective institutions.

\section{Project evaluation}

For the current project, we primarily relied upon students' written responses on the course message board, their formal peer reviews, as well as their global social justice videos, and their polished written essays for evidence. We also collected evidence from the pre-semester and post-semester COIL Career Readiness Survey as well as an attitude survey to capture their affective feelings about the COIL projects. The COIL Attitude Survey, based on a survey developed by Kayumova and Sadykova (2016), was administered at the end of the semester only and included questions regarding their affective reactions to the COIL experience, such as whether they found the COIL projects interesting, useful, thought-provoking, or confusing. Furthermore, the Career Readiness Survey, based on a survey created by the study abroad program at BMCC, included questions about students’ competencies for functioning in an international environment.

At the end of the semester, we evaluated students' responses and reflections for evidence that the COIL project had successfully achieved the stated objectives, focusing in particular on the intercultural learning objective. Due to the small size of our project, we agreed that the sample sizes of the quantitatively-focused indicators in the surveys were too small to be properly 
illustrative. Accordingly, we exclusively present students' written responses in this project. The project received institutional review board approval from BMCC, and all students consented to participate in the study.

\section{Findings}

Following a trend in broader Bahamian popular discourse, Bahamian students may come to postsecondary environments parroting negative attitudes and stereotypes regarding Haitian migrants to The Bahamas, a largely undocumented and highly-stigmatized ethnic minority (Fielding et al., 2008). We contend that COIL engagement assisted Bahamian students in denaturalizing and problematizing their received perspectives on immigrant populations; that is, working with students of diverse immigrant backgrounds, in dialogue with Rodriguez's essay, helped the students further understand, and perhaps respect, the position of others in their society. Indeed, a number of UB students noted the immigrant characteristics of their COIL partners in their responses.

One Bahamian student acknowledged in a forum post the challenges that their COIL partner faces in the United States due to their accent, discussing the strategies students use to overcome alienation to be successful in a competitive college culture. The UB student in question noted that:

"he and [Rodriguez] share the experience of being treated differently by Americans due to their accents, cultural differences, and the language barrier. Hence, in order to prevent alienation, [student name] recommends finding a solid support system because loved ones can help with jobs, schoolwork, and making new friends. This, along with the professors he has had, has encouraged him to think critically and be creative”.

As we can see above, the UB student made meaningful connections between the BMCC student's place as a linguistic outsider and their purposeful path to overcome their difficulties. Moreover, the COIL exchange encouraged UB students to think critically about the state of diversity in The Bahamas compared to other nations. One Bahamian student noted in a response that:

"The Bahamas is known nation-wide to be a Christian nation. Christian rituals are practiced in schools, households, and public events... It is uncommon to attend school or college and meet a Muslim and Buddhist. Bahamians become prejudiced against these individuals and as a result treat them differently from others. When young Bahamians are given the opportunity to attend universities across the world, it is evident that these countries are more accepting of human diversity. Human diversity is the unique biological and cultural 
variation within our species. In return it makes an individual feel accepted by society and can affect an individual positively".

As the above quote suggests, the COIL engagement encouraged UB students to ponder diversity in larger, more heterogeneous societies. This was a clear instance of intercultural learning initiated by the COIL exchange.

The COIL exchange also encouraged BMCC students to challenge their preconceived notions about Bahamian students. Some BMCC students thought that students living on small islands might not have the same opportunities for education as students in Western countries. One BMCC student explained: "You think the US is the best country to get an education, but when you hear them, I understand that they are also well-educated”. As explained in the student's testimonial, the BMCC ELL students were able to challenge their cultural biases through the COIL virtual exchange. This was yet another example of intercultural learning fostered by the COIL exchange.

As previously mentioned, the second assignment sequence in our COIL exchange gave students the opportunity to explore their home national culture/environment to prepare a YouTube presentation on a social justice topic. In the Zoom meetings leading up to students' development of their videos, students learned about the Aristotelian rhetorical appeals and brought authentic, digital images representing a social justice issue from their home nations (for students at BMCC). Some example social justice topics that students presented on included child marriages in Morocco, child sexual abuse in El Salvador, LGBT rights in The Bahamas, Boko Haram violence in Nigeria, female genital mutilation in West Africa, and school bullying in China. The assignment gave UB students the opportunity to create meaning and explain their feelings about their exposure to various injustices in the world. One UB student noted in her response to a BMCC student's global social justice video that:

"I found this presentation extremely informative. This was informative for me because I had no knowledge of this issue happening in Africa. I gained sympathy for this presentation after seeing the picture of the tools used for genital mutilation. I am a female myself and this is something I would definitely not approve of to take place on my body; this is pathetic. Something must be done to cease this issue in Africa. Females should not have to go through this”.

Furthermore, the digital media provided opportunities for students to discuss social justice issues with their COIL partners. Indeed, the COIL partner provided an answer in the discussion forum, stating: "I understand how you feel about this issue as a female but don't worry[;] now many 
organizations fight against this nonsense. Parents who force their kids to undergo female genital mutilation can go to jail”. As the above interaction suggests, some students, having not heard of these societal injustices, wanted to rationalize their understanding and respond to each other.

\section{Conclusions}

In this article, we have described our experience using COIL to initiate an intercultural exchange between a multilingual ELL classroom at a Western institution and a relatively culturally and linguistically homogeneous academic writing classroom in a Caribbean nation. As we have suggested, COIL discourse has regularly construed the presence of non-Western students as diversifying the Western classroom. These assumptions reflect a Western frame of reference. Here, the COIL exchange offered both the Bahamian students and the US-based ELL students opportunities for the internationalization of their perspectives. Further, the fact that the student populations in the different classes at the two institutions were at different English language levels, with one being traditional academic writing students, and the other being developmental ELL students, was not an encumbrance to the exchange. Rather the different levels (and backgrounds) encouraged students to engage purposefully with a student from a cultural and linguistic background previously unknown to them.

We acknowledge, however, that there were limitations to our project, and potentially, to the success of our COIL collaboration. As previously noted, our COIL collaboration took place in the fall 2020 academic semester while both campuses were operating exclusively online through digital remote learning due to the COVID-19 pandemic. While students were generally keen to participate in the COIL Zoom discussions, we did notice that some students experienced motivation issues in our classes - perhaps due to broader 'Zoom fatigue' (Nadler, 2020). For example, in the BMCC class, although a total of 17 students were registered in the class, only nine to ten generally submitted weekly assignments (for the COIL project and otherwise).

This practice report looked at collaboration between ELL students at an urban community college in the US and students at the national university of a small island Caribbean nation. For both the Bahamian students and the US-based ELL students, the COIL exchange offered opportunities for internationalization of their perspectives. Moreover, in our COIL exchange, peer-to-peer learning enhanced students' independent learning as well as provided variety to professors' teaching methods. Although BMCC immigrant students were in an urban community college, coming from different corners of the world, they evaluated their preconceived notions and perspectives about college education on a chain of small islands and social topics. Likewise, the COIL project helped the 
Bahamian students, as Winner and Shields (2002) put it in the title of their early study of a virtual exchange between a Caribbean university and a US institution, "break the island chains”. Indeed, as instructors, we take pride in organizing a platform for teaching equal opportunity (equity) and inviting diversity during a pandemic period in which distance learning has become both necessary and optimal practice.

\section{References}

Benbunan-Fich, R., \& Arbaugh, J. B. (2006). Separating the effects of knowledge construction and group collaboration in learning outcomes of web-based courses. Information \& Management, 43(6), 778-793. https://doi.org/10.1016/j. im.2005.09.001

Comeau-Kirschner, C., \& Sharar, J. (2019). A developmental writing experiment: mixing ELL and NES student writers. Journal of Basic Writing, 38(1), 5-29.

CUNY Borough of Manhattan Community College. (2020). https://www.communitycollegereview.com/cuny-borough-ofmanhattan-community-college-profile

Fantini, A. E., \& Tirmizi, A. (2006). Exploring intercultural competence. Federation EIL. https://digitalcollections.sit.edu/ cgi/viewcontent.cgi?article=1001\&context=worldlearning_publications/

Fielding, W. J., Ballance, V., Scriven, C., McDonald, T., \& Johnson, P. (2008). The stigma of being 'Haitian’ in The Bahamas. The College of The Bahamas Research Journal, 14, 38-50. https://doi.org/10.15362/ijbs.v14i0.97

Kayumova, A. R., \& Sadykova, G. V. (2016). Online collaborative cross cultural-cultural learning: students' perspectives. Journal of Organizational Culture, Communications and Conflict, 20, 248.

Kramsch, C. J. (2014). Teaching foreign languages in an era of globalization: introduction. The Modern Language Journal, 98, 296-311. https://doi.org/10.1111/J.1540-4781.2014.12057.X

Marcillo-Gómez, M., \& Desilus, B. (2016). Collaborative online international learning experience in practice opportunities and challenges. Journal of Technology Management \& Innovation, 11(1), 30-35. https://doi.org/10.4067/ S0718-27242016000100005

Moore, A. S., \& Simon, S. (2015). Globally networked teaching in the humanities: theories and practices. Routledge.

Mudiamu, S. S. (2020). Faculty use of collaborative online international learning (COIL) for internationalization at home. Unpublished doctoral dissertation. Portland State University. https://doi.org/10.15760/etd.7342

Nadler, R. (2020). Understanding "Zoom fatigue": theorizing spatial dynamics as third skins in computer-mediated communication. Computers and Composition, 58, 102613. https://doi.org/10.1016/j.compcom.2020.102613

O’Dowd, R., \& Dooly, M. (2020). Intercultural communicative competence development through telecollaboration and virtual exchange. In J. Jackson (Ed.), The Routledge handbook of language and intercultural communication (2nd ed., pp. 361-375). Routledge.

O'Reilly, C. (2021). Reflection on practice: an exploration of a virtual online collaboration as preparation for the year abroad. Journal of Virtual Exchange, 4, 50-61. https://doi.org/10.21827/jve.4.35781 
Perry, C. M. (2020). “You can’t speak Creole in here. English only”: experiences of stigma and acts of resistance among adults of Haitian descent in The Bahamas. International Journal of Bahamian Studies, 26, 61-72. https://doi. org/10.15362/ijbs.v26i0.357

Rodriguez, R. (1978). The achievement of desire: personal reflections on learning the "basics". College English, 40(3), 239-254. https://doi.org/10.2307/375783

Sairsingh, A. M., Ulentin, A., Hall Campbell-Dean, N., Curry, C., \& Ellefritz, R. (2020). The importance of diversity and inclusiveness in academia: perspectives from University of The Bahamas faculty. International Journal of Bahamian Studies, 26, 101-112. https://doi.org/10.15362/ijbs.v26i0.367

SUNY COIL Center. (2017). Guide for collaborative online international learning course development. https://www.ufpe. br/documents/40788/506683/COIL+Course+Dev+Guide+v1.6.1.pdf/fefd3ab5-a345-4a3b-9729-d1084eac5f67

Winner, T., \& Shields, T. (2002). Breaking the island chains: a case study exploring the intricate powers of language shared on the world wide web. Computers and Composition, 19(3), 273-284. https://doi.org/10.1016/S8755-4615(02)00129-9

Wylie, M. (2020). Culture and paralinguistic features !^^:-): East meets West in a virtual exchange between South Korea and England. Journal of Virtual Exchange, 3(SI-IVEC2019), 49-67. https://doi.org/10.21827/jve.3.35807 


\section{Virtual Exchange?}

Published by University of Groningen Press | UGP, a not-for-profit press

Groningen, The Netherlands | UGP@rug.nl

(C) 2022 UNICollaboration (collective work)

(C) 2022 by Authors (individual work)

Journal of Virtual Exchange 2022

Edited by Carolin Fuchs and Müge Satar

Publication date: 2022/02/25

Journal of Virtual Exchange (JVE) is an online, open-access, peer-reviewed journal aimed at practitioners and researchers in the field known variously as virtual exchange, telecollaboration, or online intercultural exchange. It is the official journal of UNICollaboration (https://www.UNICollaboration.org/), the international academic organisation dedicated to supporting and promoting telecollaboration and virtual exchange in higher-level education.

Rights. The whole volume is published under the Attribution-NonCommercial-NoDerivatives 4.0 International licence (CC BY-NCND 4.0); individual articles may have a different licence. Under the CC BY-NC-ND licence, the volume is freely available online for anybody to read, download, copy, and redistribute provided that the author(s), editorial team, and publisher are properly cited. Commercial use and derivative works are, however, not permitted.

Disclaimer. University of Groningen Press does not take any responsibility for the content of the pages written by the authors of this article. The authors have recognised that the work described was not published before, or that it was not under consideration for publication elsewhere. While the information in this article is believed to be true and accurate on the date of its going to press, neither UniCollaboration nor University of Groningen Press can accept any legal responsibility for any errors or omissions. Additionally, the publisher makes no warranty, expressed or implied, with respect to the material contained herein. While University of Groningen Press is committed to publishing works of integrity, the words are the authors' alone.

Trademark notice. Product or corporate names may be trademarks or registered trademarks, and are used only for identification and explanation without intent to infringe.

Copyrighted material. Every effort has been made by the editorial team to trace copyright holders and to obtain their permission for the use of copyrighted material in this article. In the event of errors or omissions, please notify the publisher of any corrections that will need to by incorporated in future editions of this article.

Typeset by Research-publishing.net (https://research-publishing.net)

Noto fonts are open source. All Noto fonts are published under the SIL Open Font License, Version 1.1. Noto is a trademark of Google Inc. (https://www.google.com/get/noto/).

ISSN: 2647-4832 (online only)

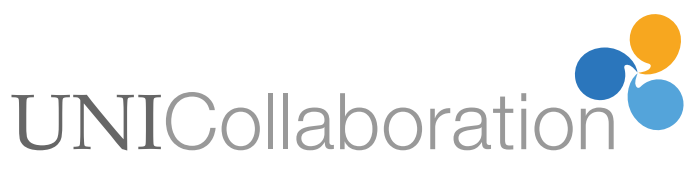

